\title{
Differential contribution of voltage-dependent potassium currents to neuronal excitability
}

\author{
Marco Arieli Herrera-Valdez ${ }^{1,2^{*}}$, Sandra D Berger ${ }^{3}$, Carsten Duch ${ }^{3}$, Sharon Crook ${ }^{1,2,3,4}$ \\ From Nineteenth Annual Computational Neuroscience Meeting: CNS*2010 \\ San Antonio, TX, USA. 24-30 July 2010
}

The excitability of a neuron depends on the different inward and outward currents that flow across its membrane. The specific role of A-type and persistent K-currents in shaping neuronal excitability remains partially unexplained by electrophysiological data. Drosophila motor neurons provide a model system to study the differential contributions of voltage-dependent K-currents to the dynamics of the membrane potential. In this work, the theoretical plausibility of existing hypotheses about the differential involvement of A-type currents in delaying spiking activity is examined through a mathematical model constructed using known macroscopic biophysical properties of voltage-dependent, slowly inactivating and fast inactivating A-type Drosophila channels. The model is constrained first by electrophysiological data, and an analysis of the membrane dynamics is performed through systematic variation of the ratios of the maximal wholemembrane currents. Different ratios among the numbers of the different channels in the model capture the basic features of responses to square pulse stimulation previously observed in Drosophila motor neurons for embryo, larvae and adult motor neurons, Kenyon cells, and giant cultured cells. The model supports the notion that slowly inactivating potassium currents are necessary for sustained spiking activity. The model also supports the hypothesis that early inactivating A-type $\mathrm{K}^{+}$(Shal) channels are responsible for experimentally observed delays in the onset of spiking. In contrast, Shaker A-type channels with more depolarized steady state inactivation also contribute to the delay to first spike, but less than Shal. Instead, Shaker channels gate single and repetitive spiking. Furthermore, the model elucidates a biophysical mechanism that allows neurons to diversify their function, in this case by combining additive and resonant

\footnotetext{
* Correspondence: Marco.Herrera-Valdez@asu.edu

${ }^{1}$ Mathematical, Computational, and Modeling Sciences Center, Arizona State University, Tempe, AZ, 85281, USA
}

properties. Our modeling results are consistent with experimental results from different preparations including Drosophila and lobster.

\section{Author details \\ ${ }^{1}$ Mathematical, Computational, and Modeling Sciences Center, Arizona State University, Tempe, AZ, 85281, USA. ${ }^{2}$ School of Mathematics and Statistics, Arizona State University, Tempe, AZ, 85281, USA. ${ }^{3}$ School of Life Sciences, Arizona State University, Tempe, AZ, 85281, USA. ${ }^{4}$ Center for Adaptive Neural Systems, Arizona State University, Tempe, Arizona, USA.}

Published: 20 July 2010

doi:10.1186/1471-2202-11-S1-P159

Cite this article as: Herrera-Valdez et al:: Differential contribution of voltage-dependent potassium currents to neuronal excitability. BMC Neuroscience 2010 11(Suppl 1):P159.

\section{Submit your next manuscript to BioMed Central and take full advantage of: \\ - Convenient online submission \\ - Thorough peer review \\ - No space constraints or color figure charges \\ - Immediate publication on acceptance \\ - Inclusion in PubMed, CAS, Scopus and Google Scholar \\ - Research which is freely available for redistribution \\ Submit your manuscript at www.biomedcentral.com/submit}

